\title{
ASSESSMENT GRAVEL AGGREGATE REACTIVITY WITH ALKALIS IN RELATION TO METHODS OF TEST
}

\author{
Z. OWSIAK ${ }^{1}$, P. CZAPIK ${ }^{1}$, J. ZAPAŁA-SŁAWETA ${ }^{1}$
}

\begin{abstract}
Alkali-aggregate reactivity (AAR) is one of the major causes of damage in concrete. Potential susceptibility of aggregates to this reaction can be determined using several methods. This study compares gravel alkali reactivity results obtained from different tests conducted on coarse aggregates with complex petrography. The potential for the reactivity in the aggregates was revealed in the chemical test using treatment with sodium hydroxide. Optical microscopy, scanning electron microscopy and X-ray diffraction were used to identify the reactive constituents. The expansion measured in the mortar bars test confirmed that the aggregate was potentially capable of alkali silica reactivity with consequent deleterious effect on concrete.
\end{abstract}

Keywords: alkali-silica reaction, aggregate, petrography, mortar,

\section{INTRODUCTION}

Aggregates occupy about $70 \%$ of the volume of concrete and have a considerable influence on its durability. Preventive measures against the premature distress of concrete due to AAR include determining the susceptibility of aggregate to this reaction. The detection of alkali-reactivity of gravel in concrete is a difficult problem, which has not been fully resolved despite extensive research efforts. The direct methods involve measuring expansion of concrete or, more frequently, mortar bars made with the aggregate being evaluated. Other methods used for the evaluation of aggregate include chemical and petrographic analyses [1,2].

This study summarises the results from reactivity tests conducted for the gravel aggregate with constituents that have different petrographic characteristics and alkali-reactivity potential. Selected problems of alkali-aggregate reaction methods are also presented, and the processes that occur during this reaction are evaluated.

The methods used and evaluated in this study include chemical analyses (PN92/B-06714-46, ASTM C 289), mortar-bar expansion tests (ASTM C 227 and ASTM C 1260), petrographic analysis, X-ray diffraction method and observations conducted

1 Kielce University of Technology, Al. Tysiąclecia Państwa Polskiego 7, 25-314 Kielce, Poland, owsiak@tu.kielce.pl,p.czapik@tu.kielce.pl,j.zapata@tu.kielce.pl 
using a scanning electron microscope. The tests indicated the need to verify further the results obtained using various procedures.

\subsection{BASIC CONCEPT OF ALKALI-AGgREGATE REACTIVITY}

The alkali-aggregate reaction is an internal corrosion of concrete that frequently leads to its deterioration. AAR is a result of a chemical reaction between sodium and potassium hydroxides dissolved in the concrete pore fluid and the silica present in the aggregate [3]. The reactivity of silica depends on its form, which has an effect on the harmful corrosion process rate. The reactive forms of silica include opal, acidic volcanic glass, tridymite, cristobalite, chalcedony, and cryptocristalline quartz and moganite as common chalcedony constituents $[3,4]$. In addition to the alkali-silica reaction, the alkali-dolomite reaction is recognized and currently regarded as a variant of the ASR by some researchers $[5,6,7]$. Alkalis enter the concrete with the cement, in which they occur as soluble sulphates of sodium and potassium. External sources of alkalis include chemical admixtures, mineral additives, aggregates, and mix water.

\subsection{EVAluation of AgGREgate REACTIVITy IN VIEW OF SPECIFICATIONS}

The alkali-aggregate reaction in concrete leads to the concrete expansion, the process that may be very slow whereas the determination of aggregate reactivity takes a lot of time. The use of the methods that allow accelerated assessment of aggregate reactivity fails to satisfy the requirement that laboratory findings reliably reflect the reality of field concrete.

Petrographic analysis belongs to the fast methods. It may help to detect reactive forms of silica and allow determining qualitative mineral composition of the aggregate. Observations conducted using an optical microscope provide an additional source of information about the petrographic composition of the gravel aggregate. To detect silica present in the aggregate petrophraphic analysis can be supplemented with X-ray analysis and scanning electron microscopy.

The chemical methods determine the degree of alkali reactivity of aggregate from the reactive silica content. In the tests, the loss in mass of the aggregate subjected to the sodium hydroxide solution at $90^{\circ} \mathrm{C}$ is measured [8], and the solution at $80^{\circ} \mathrm{C}$ is analysed for silica dissolved and reduction in alkalinity [9]. The test results are compared within the specifications that define three reactivity levels for the aggregate. Non-reactive aggregates display zero or low reactivity. If the potential reactivity level is determined to be class 1 or class 2, mortar bar tests have to be done for the final assessment. Class 1 aggregates are potentially alkali-reactive and can be used to produce concrete elements that will not be exposed to a constant source of moisture or a short-term action of moisture and elevated temperatures. Class 2 materials can be used with cements containing 
small amounts of sodium and potassium $\left(\mathrm{Na}_{2} \mathrm{O}_{\mathrm{e}}<0,6 \%\right.$, cement content $\left.<500 \mathrm{~kg} / \mathrm{m}^{3}\right)$ or with cements containing pozzolanic additives.

To sum up, from among the standard alkali-reactivity investigation methods, the prevailing and conclusive method is that which involves the use of the mortar bars fabricated with the subject aggregate and the cement with the increased sodium and potassium content. The required duration of the test [10] of up to 180 days may be too short for the slowly reacting aggregates such as granites or quartzite. On the other hand, the required waiting period may be too long for the operative aggregate quality control.

The most popular mortar bar method is the test method specified in ASTM C 227 [11]. It involves casting mortar bars with the aggregate processed to the recommended gradation and industrial cement with the maximum $\mathrm{Na}_{2} \mathrm{O}_{\mathrm{e}}$ content available. The bars are stored over water at a temperature of $38^{\circ} \mathrm{C}$, at which the swelling is accelerated and may be higher than that obtained at higher or lower temperatures. Aggregates are classified as reactive if the expansion value is higher than $0.05 \%$ within the first three months or $0.1 \%$ in the later period. To reduce the test duration, accelerated procedures have been developed. They include increasing the storage temperature to $80^{\circ} \mathrm{C}$ and immersing the bars in sodium hydroxide solution (ASTM C 1260) [12]. If expansion measured after 16 days exceeds $0.1 \%$, the aggregate is rendered potentially reactive or reactive if the value is higher than $0.2 \%$. The testing conditions do not reflect field conditions in which the aggregate is incorporated in concrete.

The results from the mortar bar expansion test conducted to ASTM C 227 show a very good correlation with the aggregate behaviour in concrete structures, but a long time is needed for the decision to be made regarding the suitability of the given aggregate.

On the other hand, the results of rapid chemical tests are not conclusive. Likewise, petroghaphic analysis, whilst very helpful in identifying mineral constituents, fails to indicate whether the given mineral will cause concrete expansion.

\section{Materials And METhods}

The study used glacial gravel aggregate pre-processed to $0 / 16 \mathrm{~mm}$ fraction and two Portland cement types CEM I 42.5 with similar $\mathrm{Na}_{2} \mathrm{O}_{\mathrm{eq}}$ content and compositions as in Table 1.

Table 1.

Cement chemical compositions

\begin{tabular}{|c|c|c|c|c|c|c|c|c|c|c|c|c|}
\hline Cement & $\mathrm{SiO}_{2}$ & $\mathrm{Al}_{2} \mathrm{O}_{3}$ & $\mathrm{Fe}_{2} \mathrm{O}_{3}$ & $\mathrm{CaO}$ & $\mathrm{MgO}$ & $\mathrm{SO}_{3}$ & $\mathrm{~K}_{2} \mathrm{O}$ & $\mathrm{Na}_{2} \mathrm{O}$ & $\mathrm{Na}_{2} \mathrm{O}_{\mathrm{eq}}$ & $\mathrm{TiO}_{2}$ & LOI & Cz. n.r. \\
\hline $\mathrm{A}$ & 20.20 & 4.80 & 3.00 & 61.70 & 1.80 & 2.70 & 0.78 & 0.15 & 0.66 & 0.45 & 3.00 & 1.00 \\
\hline $\mathrm{B}$ & 21.50 & 4.25 & 4.00 & 63.50 & 0.60 & 2.45 & 0.55 & 0.28 & 0.64 & 0.07 & 2.45 & 1.50 \\
\hline
\end{tabular}

LOI - loss on ignition, cz.n.r. - HCl-insoluble parts 
Aggregate susceptibility to alkali corrosion was investigated using chemical methods to PN-92/B-06714-46 [8] and ASTM C 289-94 [9]. Fractions $1 \div 2,2 \div 4,4 \div 8$ obtained as a result of mechanical crushing, and fraction $8-16 \mathrm{~mm}$ sieved from the natural-state aggregate were studied in accordance with PN-92/B-06714-46. The loss in mass in fractions $1 \div 2$ and $2 \div 4$ was measured after a 1 -hour bath in a $4 \%$ solution of $\mathrm{NaOH}$ at $90^{\circ} \mathrm{C}$, removal of hydroxyl ions and drying to the solid mass. The loss in mass in fractions $4 \div 8$ and $8 \div 16$ was measured after a 1 -hour bath in a $10 \%$ solution of $\mathrm{NaOH}$ at $90{ }^{\circ} \mathrm{C}$, removal of hydroxyl ions and drying to the solid mass. In addition, the grains of fractions $4 \div 8 \mathrm{~mm}$ and $8 \div 16 \mathrm{~mm}$ were separated according to their colour, fracture, lustre, texture and porosity. The X-ray analysis and petrographic examination were performed on the selected groups of reactive rocks. The scanning electron microscope with an EDS detector was used to analyse the polished surfaces of the rocks. The petrographic analysis of the aggregate was performed on specimen sections in transmitted light. The tests according to ASTM C 289-94 were carried out on $0.150 \div 0.300 \mathrm{~mm}$ fraction obtained by crushing the gravel aggregate. Expansion of mortar bars made with cements A and B was measured according to ASTM C 1260 [12] for 49 days. Expansion of the bars made with cement A was measured to ASTM C 227 using the Graff-Kaufman apparatus for 180 days [11]. The expansion increment in each measurement was obtained by averaging the linear change results recorded for 5 mortar bar samples $25 \times 25 \times 250$ $\mathrm{mm}$.

\section{RESULts}

As shown in Figure 1, aggregate reactivity results from the chemical tests vary. The loss in mass analysis conducted in the $\mathrm{NaOH}$ bath test in accordance with PN92/B-06714-46 [8] (Figure 1a) gave the values that classified the gravel aggregate as potentially reactive. The loss in mass for all fractions investigated $(1 \div 2,2 \div 4,4 \div 8$ and $8 \div 16 \mathrm{~mm}$ ) was in the range from 0.5 to $2 \%$. In the test determining the alkalinity of $\mathrm{NaOH}$ solution and the content of silica dissolved from the aggregate, carried out to ASTM C 289-94 [9] (Figure 1b), the subject gravel was identified as reactive aggregate. 

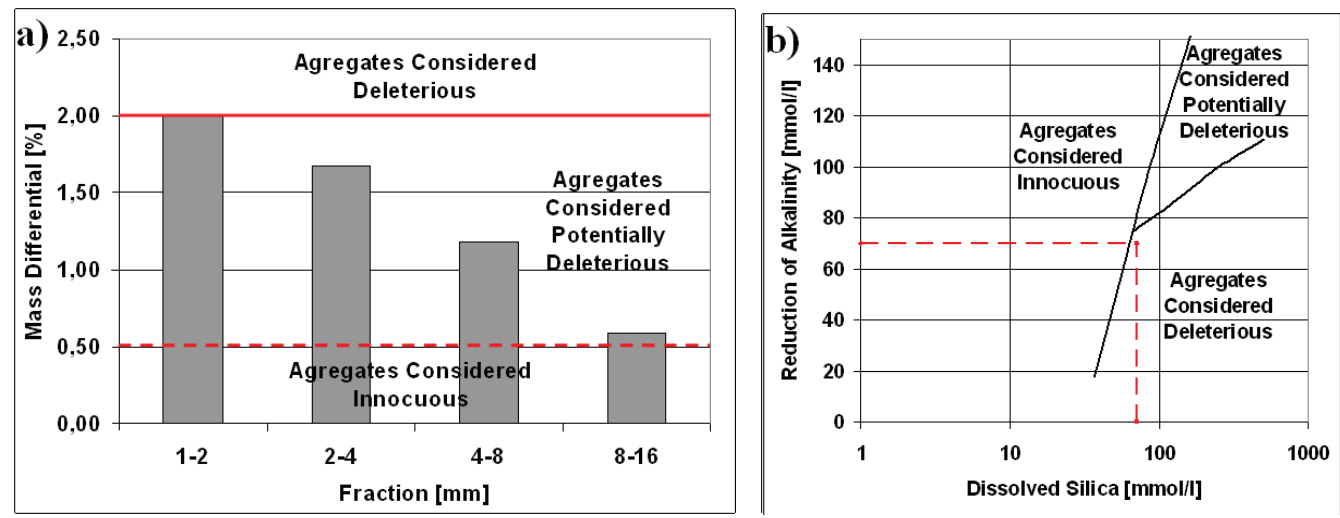

Fig. 1. Gravel aggregate reactivity acc. to: a) PN-92/B-06714-46, b) ASTM C 289-94

The loss in mass was determined for $4 \div 8 \mathrm{~mm}$ and $8 \div 16 \mathrm{~mm}$ fraction grains divided into groups according to colour, fracture, lustre, texture and porosity [8], which helped identify the parent rocks that enter into reactions with alkalis. Four selected types of rock were analysed petrographically and by X-ray diffraction. The following rocks were identified using the thin section analysis of the aggregate grains under an optical miscoscope in transmitted light: quartz-glauconitic sandstone with clay and carbonate cement (Figure 2a), organodetritic limestone with sparitic and micritic cement, quartz pyroxene schist with opaline cement, and feldspathic granite with biotite (Figure 2b). Table 2 summarises the results from the quantitative analysis of reactive constituents found in these rocks.
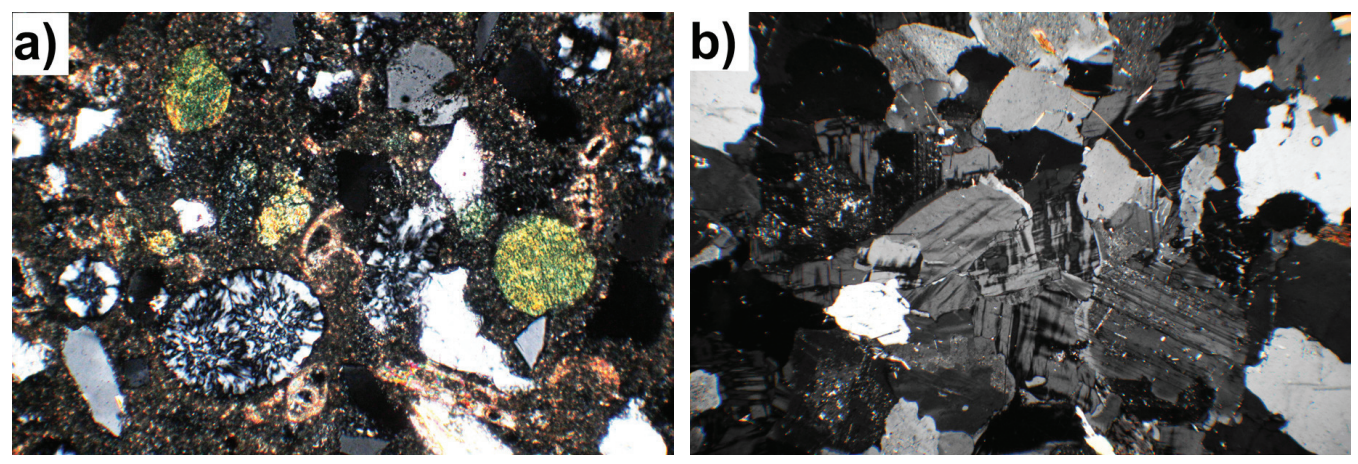

Fig. 2. Texture of reactive rocks (magn. 120x): a) Opal in quartz-glauconitic sandstone b) strained quartz in feldspathic biotite granite 
Table 2.

Reactive constituents of gravel aggregate

\begin{tabular}{|l|c|c|c|}
\hline \multirow{2}{*}{ Rock type } & \multicolumn{3}{c|}{ Reactants [\% vol] } \\
\cline { 2 - 4 } & Chalcedony & Quartz & Opaline cement \\
\hline $\begin{array}{l}\text { Clay-carbonate cemented quartz-glauconitic } \\
\text { sandstone }\end{array}$ & 2.1 & - & - \\
\hline Organodetritic limestone with sparite and micrite & \multicolumn{2}{|c|}{0.1} & - \\
\hline Quartz pyroxene schist with opaline cement & - & - & 47.0 \\
\hline Feldspathic granite with biotite & - & $15.7^{*}$ & - \\
\hline
\end{tabular}

* strained quartz

The petrographic analysis helped identify three constituents that may be responsible for the gravel alkali reactivity: chalcedony, opal and strained quartz [3, 4]. A small amount of quartz was detected in the organodetritic limestone. Well-crystallised quartz is considered non-reactive. But its cryptocrystalline form, such as chalcedony, dispersed in the limestone is usually regarded responsible for reactivity of limestones [13]. This mineral is also accompanied by moganite, which is a very reactive silica polymorph [4].

Well-crystallised quartz may be reactive if strained, which may take place in granites (Figure 2b) [3].

The phase compositions of the rock samples determined in petrographic examination were confirmed by X-ray analysis. The phase composition analysis of the organodetritic limestone confirmed the presence of quartz, which can occur in the form of chalcedony (Figure 3a). The X-ray analysis of the bulk gravel indicated the presence of such minerals as quartz, calcite, dolomite and feldspar (albite-anorthite), which occur with clay minerals (illite, chlorite) (Figure 3b). 
a)

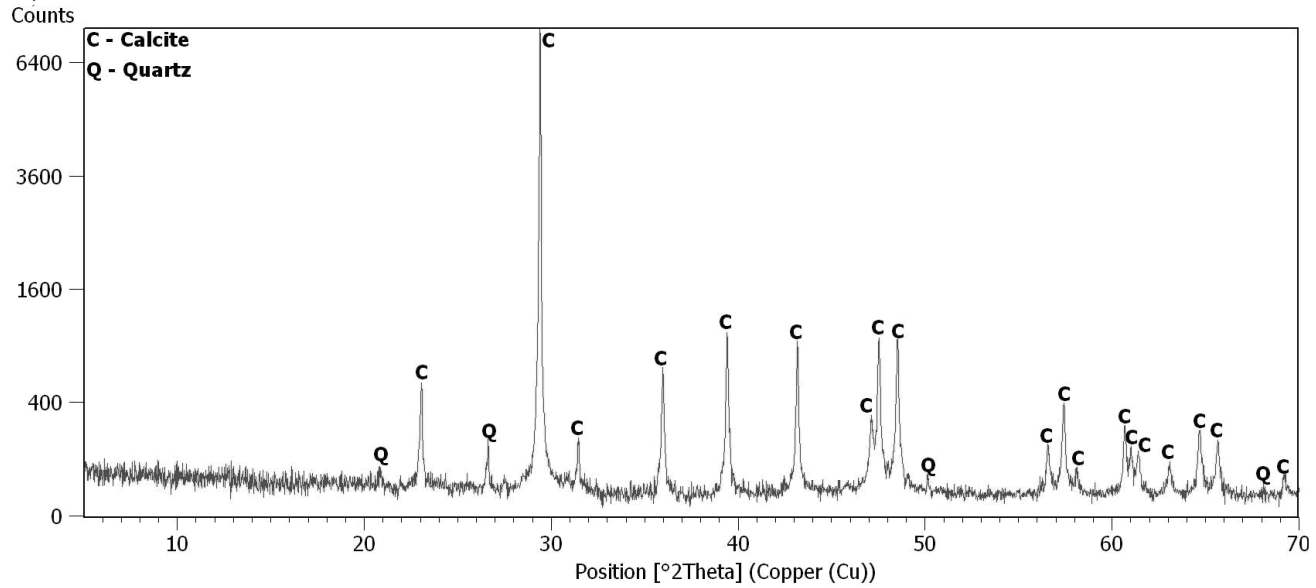

b)

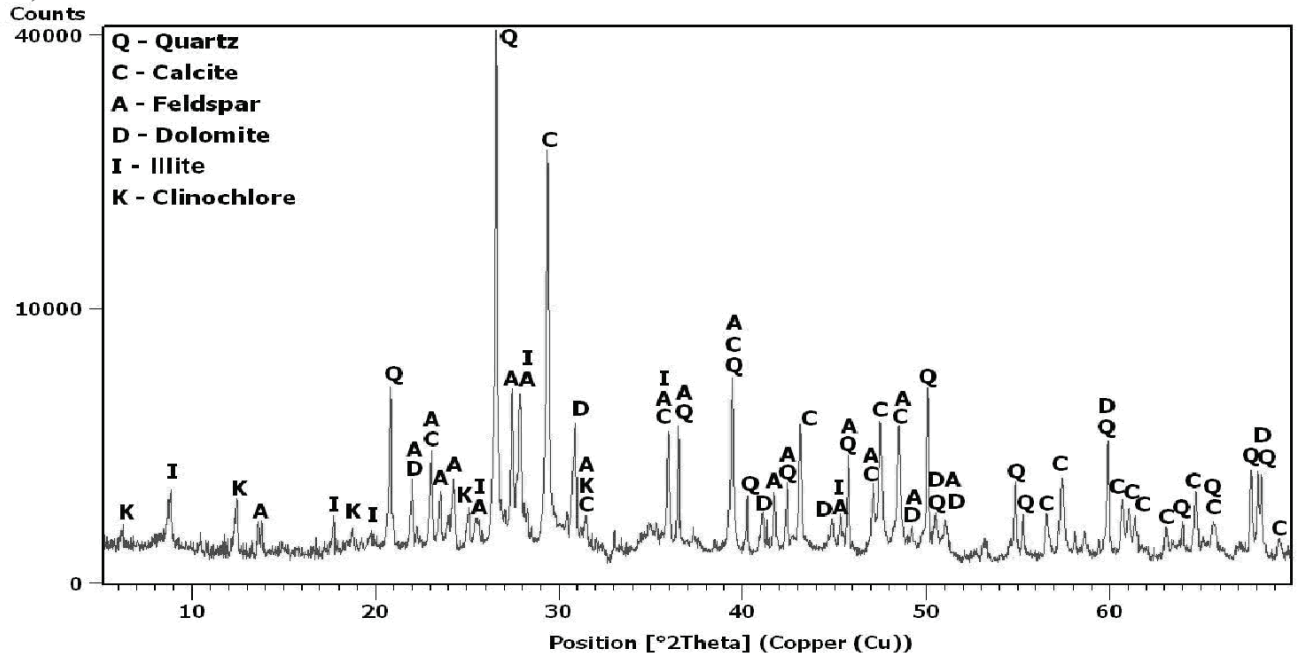

Fig. 3. X-ray analysis of a) limestone with reactive silica, b) gravel aggregate.

Scanning electron microscope analysis in combination with EDS X-ray microanalysis of the polished slides revealed the presence of chalcedony dissolved in the carbonate cement of the quartz-glauconitic sandstone (Figure 4a) and organodetritic limestone (Figure 4b). Dispersed grains of chalcedony present in the sandstone carbonate cement did not exceed $5 \mu \mathrm{m}$. Fewer grains of chalcedony are detected in the limestone than in the sandstone. Thin veins of opal were visible in the schist (Figure 4c). 

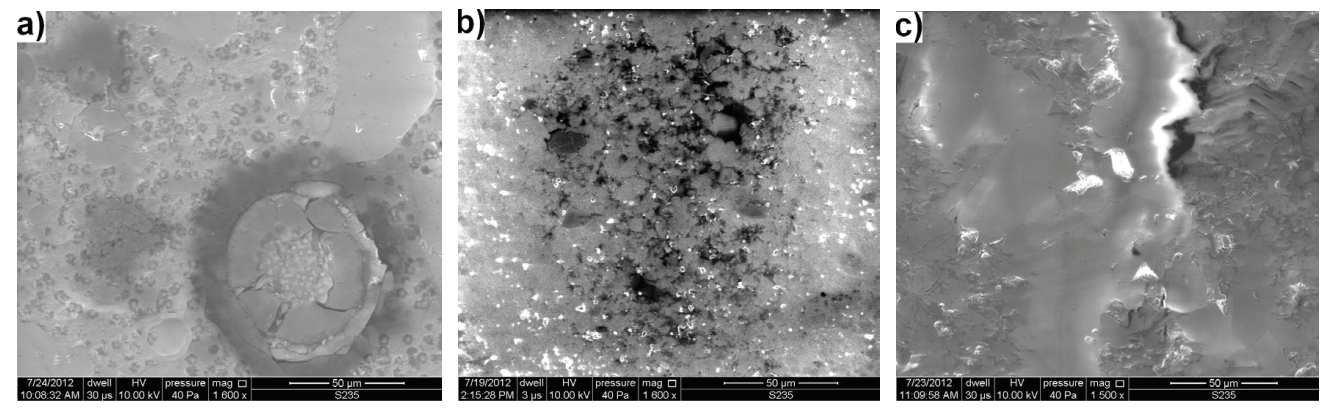

Fig. 4. Microstructure of reactive rocks (mag 1600x): a) illite carbonate-cemented quartz-glauconitic sandstone, b) organodetritic limestone with sparite and micrite, c) quartz pyroxene schist with opaline cement

Mortar bar expansion is a measurable effect of the alkali-silica reaction. Figure 5 presents the results from the expansion tests conducted on mortar bars made with reactive gravel aggregate. There are similarities and differences between the behaviours of mortars stored in the conditions promoting the alkali-aggregate reaction (Figure 5a) (accelerated test) and those stored in the conditions similar to those encountered in service (Figure 5b) (long-term test). Both methods indicated that after the initial stage of the reaction, between measurement 0 " and 1" (at 1 and 14 days respectively, according to a) ASTM C 1260, b) ASTM C 227) there was a rapid increase of expansion.
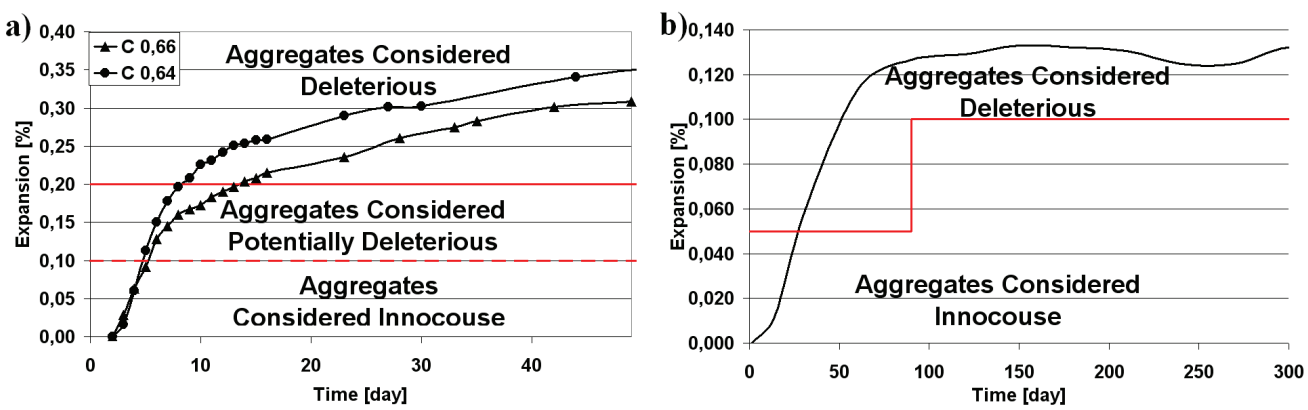

Fig. 5. Expansion of mortars with reactive aggregate: a) ASTM C 1260, b) ASTM C 227

The expansion of the mortar bars made with cement A increases under accelerated conditions (ASTM C 1260) up to $0.145 \%$, and in the case of cement B mortar bars - up to $0.23 \%$ (Figure $5 \mathrm{a}$ ) on the tenth day. Under conditions similar to those encountered in service (ASTM C 227), the expansion value for the mortar bars made with cement A reaches the level of $0.128 \%$ at 90 days (Figure 5b). After that, under the accelerated 
conditions the expansion growth rate decreases. In the long-term test expansion stabilizes after a period of an extensive growth. Both methods classed the subject gravel aggregate as reactive. In the accelerated tests, the expansion reached the threshold value at 3 days for the potentially reactive aggregates and at 12 days for the reactive aggregates. In the long-term tests, the mortar bar expansion exceeded the boundary value of $0.5 \%$ at 27 days (expansion value of $0.5 \%$ is the boundary value for reactive aggregates through the first 90 days of measurements).

The accelerated method revealed the effect of the cement type on the expansion rate. The expansion recorded for the mortar bars made with cement $\mathrm{B}$ was $0.05 \%$ higher from the 6th day than that recorded for the mortar bars made with cement A measured at the same time intervals.

\section{Discussion}

The methods used in this study indicate that the subject gravel aggregate is alkali reactive in concrete. The results obtained from the tests carried out to PN-92/B-06714-46 [8] enabled the tested gravel to be classified as potentially reactive, whereas the results from the other tests identified it as unequivocally alkali reactive. In the chemical method [8] the aggregate with 1 to $16 \mathrm{~mm}$ grain size grouped in fractions was tested. The loss in mass of the aggregate stored in the hydroxide solution increases with the increasing degree of its fineness [14] indicating a higher level of its reactivity (Figure 1a). In the chemical method [9], and in the mortar bar expansion tests $[10,11]$ coarser aggregate is used. The phase analysis of the aggregate tested by various methods provided information that supplemented the other data. The X-ray analysis allowed fast determination of mineral composition of the aggregate, and the detection of silica in the grains of the organodetritic sparitic-micritic limestone (Figure 3a) suggested the presence of alkali reactive constituents in the aggregate.

Petrographic methods in conjunction with optical microscopy in transmitted light helped identify mineral constituents of the aggregate, including those that might be alkali reactive. Scanning microscopy, owing to greater magnifications it offers, facilitates observations of reactive silica grains distributed in the rock's cement (Figs. 4a and 4b). The data obtained from the tests described above refer to only one component necessary to start the alkali-aggregate reaction. The tests on mortar or concrete specimens provide information about compatibility of the aggregate with concrete components. Expansion is a clearly visible and measurable effect of the occurrence of the alkali-aggregate reaction in concrete. The duration of the test can be reduced when the alkali-aggregate reaction is accelerated $[12,16]$, by storing the specimens at an elevated temperature in a highly alkaline environment. The comparison of mortar bar expansion results obtained from accelerated and long-term tests confirms that the accelerated conditions help classify the aggregates as reactive within the period 15 days shorter than the long-term tests. 
The continuous growth of expansion in the accelerated mortar bar test can be explained by the supply of the sodium and potassium ions from the solution in which the specimens are stored. Stabilization of the bar length in the long-term test following a rapid expansion growth between day 14 and day 90 may indicate that one of the reaction substrates, sodium and potassium ions derived from the mortar constituents, has depleted. It can be assumed that the alkalis from the mortar constituents are responsible for only the initial intensive growth of expansion.

In the accelerated tests, the initial rapid expansion ended after 6 days and the linear deformation of the specimens reached the value of $0.145 \%$. The mortar bars reached the reactivity limit $(0.2 \%)$ at 12 days in the accelerated test due to access of alkalis from the $\mathrm{NaOH}$ solution. In the long-term test, expansion stabilized at about $0.128 \%$ at 90 days of measurements. These similar results referring to the end of intense expansion confirm the depletion of alkalis from the tested mortar specimen cements.

High values of expansion at the initial stage of the long-term tests may result from the fact that the carbonate aggregate containing reactive silica accelerates the alkali-silica reaction [15]. This aggregate type is represented here by quartz-glauconitic sandstone with clay and carbonate cement and by organodetritic sparitic-micritic limestone. Their high reactivity may be due to the presence of a very reactive moganite, which co-occurs with chalcedony.

The type of the cement used had an effect on the total expansion values in the accelerated tests. The cements A and B belonged to the same class and had a similar value of $\mathrm{Na}_{2} \mathrm{O}_{\text {eq }}, 0.66$ and 0.63 , respectively. However, the expansion of the mortar bars made with cement $\mathrm{B}$ was higher that that of the mortar bars made with cement $\mathrm{A}$. It has to be noted that cement $\mathrm{B}$ had a higher $\mathrm{Na} / \mathrm{K}$ ratio compared with cement $\mathrm{A}$.

\section{Conclusions}

As a result of the work carried out, the following conclusions can be made:

- the chemical method (ASTM C 289-94 [9]) provides a means to quickly determine potential alkali reactivity of the tested aggregate. However, the results are affected by the very fine nature of the subject aggregate, which increases the surface area considerably enhancing the potential for reaction [12],

- the chemical test involving measuring the loss in mass (PN-92/B-06714-46 [8]) gave underestimated reactivity results for coarser aggregate fractions relative to the results from other methods. The increase in the reactivity of the aggregate with increasing degree of fineness was also confirmed. This method may help differentiate reactive rocks in the gravel aggregate that has a diversified petrographic composition,

- the petrographic examination and phase analysis of the aggregate enabled reactive minerals to be identified. Determining the presence and quantity of reactive constituents in the aggregate helps define the type and dynamics of the alkali-aggregate reaction [15], 
- the accelerated mortar bar expansion method gives fairly rapid indication of potential expansive reactivity in concrete. In this method, the degree of expansion is influenced by the presence of reactive constituents in the mortar and the quantity of alkali ions from the solution in which the samples are stored.

\section{REFERENCES}

1. Z. Owsiak, J. Zapała, "The Evaluation of the Laboratory Methods Applied in the Identification of the Alkali-Silica Reaction", TRANSCOM 2011 9th European conference of young research and scientific workers, Žilina. 117-120, 2011

2. Z. Owsiak, P. Czapik, "The Classification of the Testing Methods for Alkali-Carbonate Reaction", TRANSCOM 2011 9th European conference of young research and scientific workers, Žilina, 111-115, 2011

3. W. Kurdowski, The Chemistry of Cement and Concrete (in Polish), SPC, Cracow, 2010

4. M.A.T.M. Broekmans, "Structural properties of quartz and their potential role for ASR", Material Characterization, 53, 129-140, 2004

5. T. Katayama, "The So-called Alkali-Carbonate Reaction (ACR) - Its Mineralogical and Geochemical Details, with Special Reference to ASR", Cement and Concrete Research, 40, 643-675, 2010

6. T. Katayama, "How to Identify carbonate rock reaction in concrete", Materials Characterization, 53, 85-104, 2004

7. P. E. Grattan-Bellew, et al. "Is Alkali-Carbonate Reaction Just a Variant of Alkali-Silica Reaction ACR $=$ ASR", Cement and Concrete Research, 40, 556-562, 2010

8. PN-92/B-06714-46 Mineral aggregates - Testing - Determination of alakaline reactivity by rapid method (in Polish),

9. ASTM C 289-94 Standard Test Method for Potential Alkali Silica Reactivity of Aggregates (Chemical Method),

10. PN-B-06714-34:1991/Az1:1997 Mineral aggregates - Testing - Determination of alakaline reactivity (in Polish),

11. ASTM C 227-10 Standard Test Method for Potential Alkali Reactivity of Cement- Aggregate Combinations (Mortar-Bar Method),

12. ASTM C1260 - 07 Standard Test Method for Potential Reactivity of Aggregates (Mortar-Bar Method),

13. I. Sims, P. Nixon: "RILEM Recommended Test Method AAR-1: Detection of potential alkali-reactivity of aggregates - Petrographic method", Materials and Structures, 26, 480-496, 2003

14. S. Multon et al. "Effect of aggregate size and alkali content on ASR expansion", Cement and Concrete Research 40, 508-516, 2010

15. V. Jensen V. "Reclassification of alkali aggregate reaction", $14^{\text {th }}$ International Conference of AlkaliAggregate Reaction, Austin, TX USA, 20-25 may 2012,

16. W. Kurdowski, A. Garbacik, B. Trybalska: „Application of accelerated test ASTM C1260 to aggregate containing calcium carbonate ", Cement-Lime-Concrete, 6, 339-348, 2005 
